\title{
Visual Music
}

\author{
Terry Trickett \\ London NW8 9RE, UK \\ terrytrick@btinternet.com
}

\section{INTRODUCTION}

Visual Music has a short history. It can be argued that the idea was initiated, in the 1920s, by Oscar Fischinger who was active as an artist in Frankfurt and Berlin. He invented techniques whereby a series of frames, showing abstract images, were put together as short films. His innovation caught the attention of Hollywood where, in 1926, he emigrated but, unfortunately, achieved only very limited success. Walt Disney used some of his ideas in Fantasia but gave him no credit. Earlier this year, I took part in the Punto y Raya Festival 2014 held in Reykjavik. Here, the intrinsic relationship between music and abstract images was explored by 80 or so artists from all around the world. I think we can say that now, almost a century after Fischinger, Visual Music has come of age!

\section{CAVALCADE}

To demonstrate my own approach to the subject, I will first perform 'Cavalcade'. As with many of my pieces, the initial visual idea was sparked off by a musical composition for clarinet. Apart from developing the idea visually, I use my skills as a clarinettist to provide the sound track. Cavalcade generates a series of contrasting episodes with a common geometric link - circles. As a start, I make a set of movies from image sequences produced by manipulating Processing code. For me, it's a process of trial and error, involving mathematical adjustments to the number of shapes, the way they're set in motion and the randomisation of their colour. Eventually, I create a vocabulary of film clips (see Figure 1) that reflect, in one way or another, my initial vision for the piece. Then, using After Effects, I match my film clips against the musical phrases in my chosen piece, sometimes overlaying several clips together.

\section{NEURAL PATHWAYS}

Cavalcade's celebration of circles was produced last year. This year, l've moved on to the much more complex geometric shapes of Islam. As one of many architects fascinated by the surface ornamentation of Muslim buildings, I've visited mosques and temples in India and elsewhere.

I've taken just one Islamic pattern as a start point for an ambitious project which aims to trace the neural pathways of the human brain. It's a linear pattern (see Figure 2) which, multiplied many times over, provides me with a 'texture' that can be built into Processing code. l've produced a video of the result but, for the moment, let me show you just a few stills (see Figure 3 )

They're a fiction, of course, rather than a neuroscientific reality but my aim is to show something of the complexity of the human brain. It's the axons of 30 billion, or so, neurons that take up all the available space in our brains. My images show only 5,000 of these meeting and engaging with one another to simulate how we create, in our minds, a memory, an idea or a thought. The biological mechanism involved remains a mystery; nobody knows how we do it.

\section{THREE ARABESQUES}

Continuing my theme of Islamic geometry, I'll turn now to another piece of visual music - Three Arabesques. It's based on a duet for two clarinets by Francis Poulenc.

In the past, Islam was far ahead of the West in producing complex art forms based on the dynamic mathematical concept of trigonometry. Now, through coding, artists in the West can take delight in assembling mathematically defined forms which 'confound the eye of the beholder'.

For Three Arabesques, I've chosen to play a mathematical game based on hexagons - a common theme in Islam. But my variations on the theme can extend way beyond the restrictions imposed on Islamic ceramicists; through Processing code, I produce patterns which take flight into a realm of geometric fantasy. As you will see, I reveal a sequence of events which enables a 
set of disparate hexagons, in many colours, to converge in a multiplicity of ways. (See Figures 4, 5 and 6)
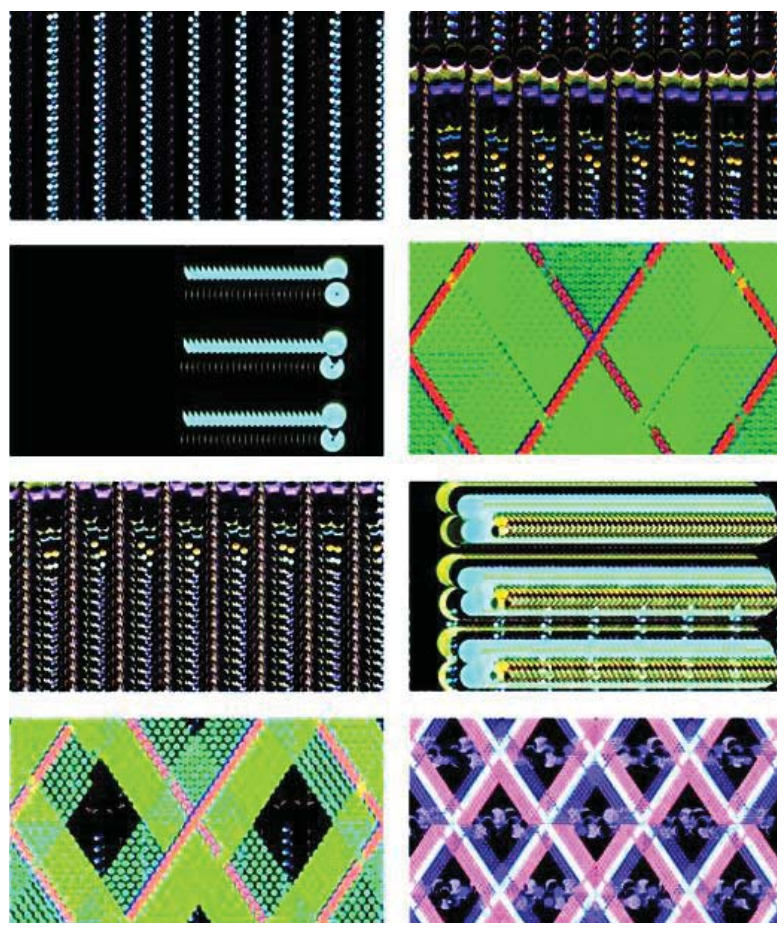

Figure 1: Just a few film clips from Cavalcade
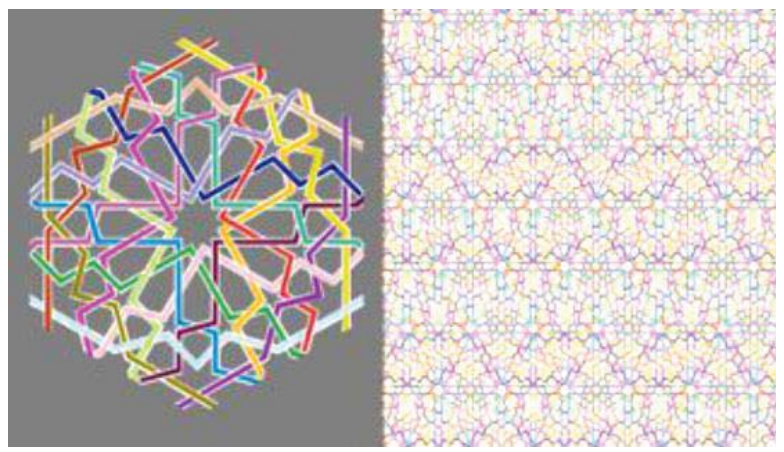

Figure 2: Linear Islamic pattern multiplied many times to create 'texture'

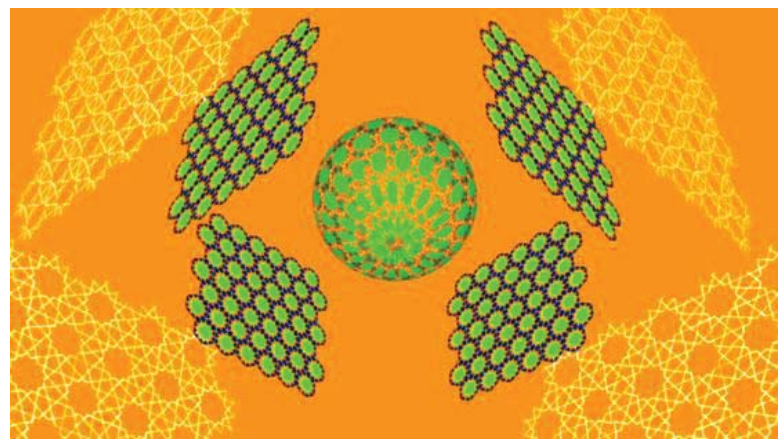

Figure 4: First Arabesque
In performing this work, I play one part of Poulenc's clarinet duet live; the other part is recorded. As you will hear, the composer's sound world embraces, appropriately, both tonal and modal harmonies.

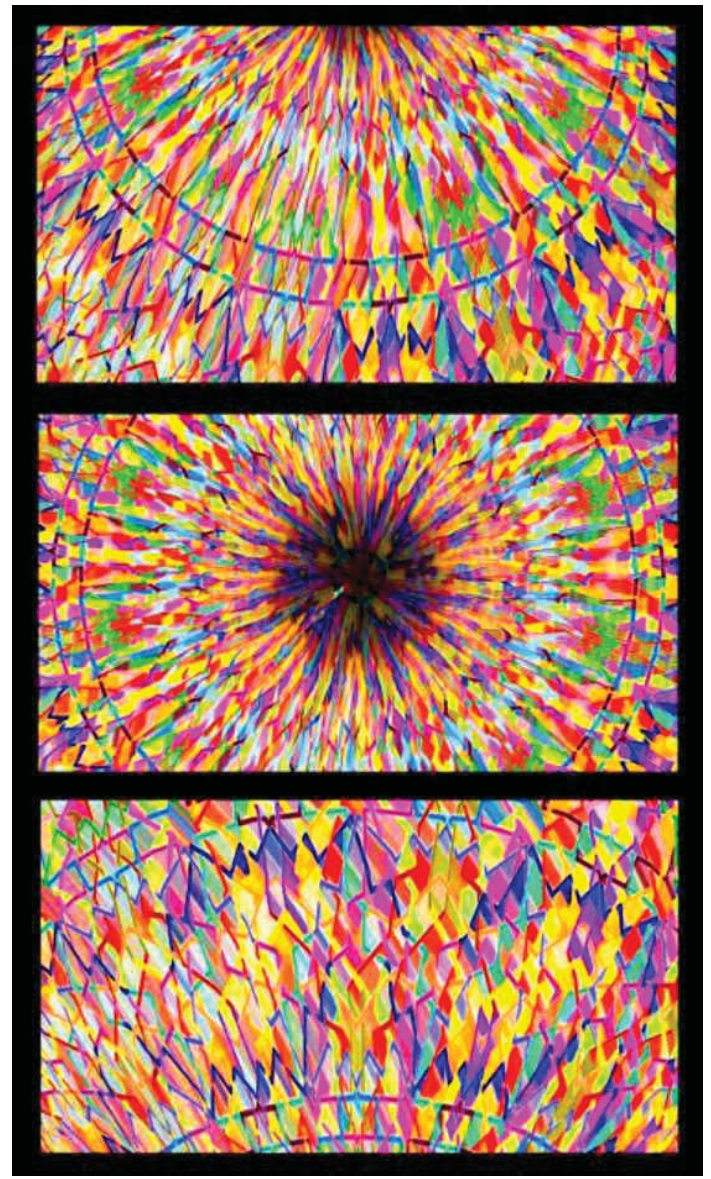

Figure 3: Stills from Neural Pathways

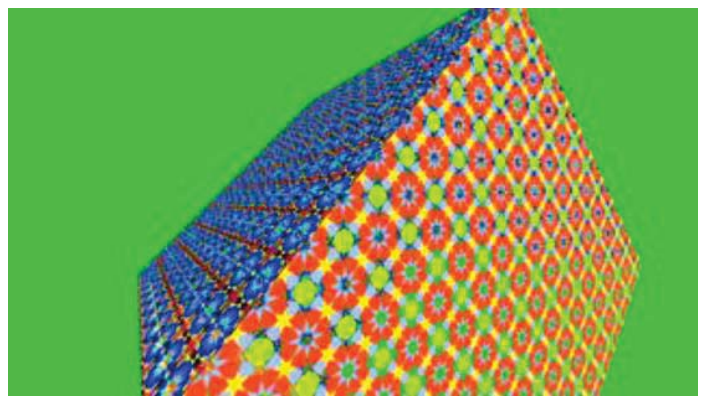

Figure 5: Second Arabesque

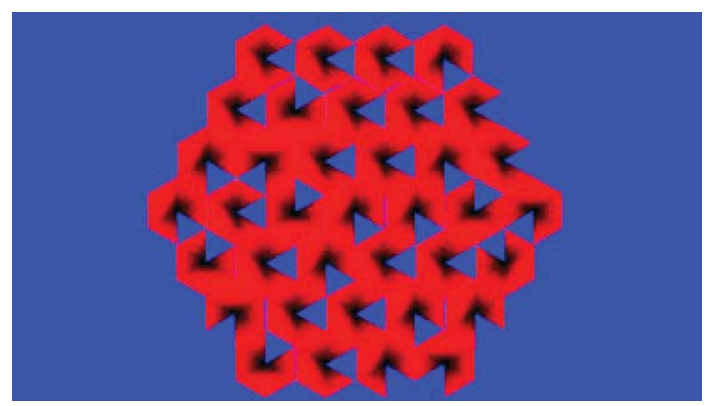

Figure 6: Third Arabesque 